\title{
Mechanism of Propolis Affecting Oral Flora Structure and Immune Microenvironment of Oral Mucositis in Patients with Leukemia Undergoing Chemotherapy
}

\author{
S. T. LV AND Q. L. QU*
}

Department of Stomatology, Yantai Affiliated Hospital of Binzhou Medical University, Shandong, Yantai 264100, China

Lv et al.: Mechanism of Propolis Affecting Oral flora Structure and Immune Microenvironment of Oral Mucositis

To explore the mechanism of the effect of propolis on the oral flora structure and immune microenvironment of oral mucositis in patients with leukemia after chemotherapy. According to the principle of clinical research guidance of antibacterial drugs, the curative effect of leukemia chemotherapy patients after propolis treatment was judged, the bacteriological detection method was used to detect the species, detection amount and composition ratio of oral flora in the oral cavity and reverse transcription polymerase chain reaction, enzyme-linked immunoassay and western blot were used to detect the messenger ribonucleic acid expression of interleukin 22 and tumour necrosis factor alpha in the oral mucosa of patients, the levels of chemokines, chemokine (C-X-C motif) ligand 9 and chemokine (C-X-C motif) ligand 10 and the expression of interleukin 22 and tumour necrosis factor alpha proteins. After $2 \mathrm{w}$ of chemotherapy, the incidence of oral mucositis was increased and the number of neutrophils was decreased. Besides, the bone marrow hyperplasia was aggravated at the same time compared with the control group, the propolis treatment group had higher cure rate of oral mucositis, neutrophil recovery time, total bacterial count, interleukin 22 and tumour necrosis factor alpha messenger ribonucleic acid expression, chemokine (C-X-C motif) ligand 9 and chemokine (C-X-C motif) ligand 10 levels and expression levels of interleukin 22 and tumour necrosis factor alpha proteins. Propolis could reduce the symptoms of oral mucosal inflammation after leukemia chemotherapy, adjust the structure of oral flora and improve the oral immune microenvironment by reducing the expression of inflammatory factors.

Key words: Propolis, leukemia, chemotherapy, oral mucosa, immune microenvironment

Propolis is a gelatinous substance with aromatic smell, which is mainly the mixture of gum collected by bees from plant buds or trunks and jaw gland secretions and beeswax. It is an important medium for bees to resist and protect against pests and diseases and pathogenic microorganisms ${ }^{[1]}$. Many researchers suggest that phenols, flavonoids, aldehydes, coumarins, lactones and other components in propolis have good pharmacological effects. Thus, it can be used for antivirus, anti-bacteria, anti-inflammation and analgesia treatment and can effectively inhibit and kill periodontal pathogens. It also can relieve clinical symptoms such as gingival bleeding, gingival pain and halitosis in clinical practices $^{[2]}$. At the same time, it is reported that propolis can promote the repair and regeneration of tissues ${ }^{[3]}$.
At present, the allergy and drug resistance of chemical drugs are increasingly serious. Propolis, as a natural and efficient medicinal material, has been applied to the prevention and treatment of oral diseases, with unique and important advantages ${ }^{[4]}$.

Oral mucosa is a kind of mucosal tissue composed of non-keratinocyte squamous cells, which can be regenerated within 1-2 w. Its underlying tissues are mainly sebaceous and salivary glands and the integrity of its structure and function has an important relationship with the oral health of the body ${ }^{[5]}$. It is found that leukemia patients are easy to have oral complications after chemotherapy, which seriously affects the living quality of patients and may cause systemic infection in

*Address for correspondence

E-mail: quqianli1978@126.com 
severe $\operatorname{cases}^{[6]}$. Therefore, in the treatment of leukemia, oral care of patients is an effective way to reduce and prevent oral complications, which can prevent infection of patients and improve the therapeutic effect. Studies have found that chemotherapy drugs taken by leukemia patients have direct killing effect on the epithelial cells of oral mucosa of patients. They destroy the tissue renewal of oral mucosa and then lead to oral mucosal ulceration ${ }^{[7]}$. At the same time after chemotherapy, the patient's medullary hematopoiesis function is altered, which leads to the decrease of neutrophils. Moreover, the patient's drinking less water after chemotherapy leads to the proliferation of normal flora in the oral cavity, which obviously reduces the self-cleaning ability of the oral cavity producing amines and indoles causing halitosis and finally destroys the oral environment and induces oral mucosal injury and oral ulcer ${ }^{[8]}$. However, after taking a large amount of glucocorticoids and antibiotics in the course of treatment, the patient's internal flora is out of balance. The competitiveness of normal flora growth is weakened and some fungi and pathogenic bacteria proliferate abnormally, resulting in aggravation of oral infection ${ }^{[9]}$. It is also reported that the treatment method often used in bone marrow transplantation of leukemia patients is mainly to give patients high-dose radiotherapy, which will cause molecules in patients to be excited or ionized, then reduce gland secretion and finally result in dryness and direct injury of oral mucosa ${ }^{[10]}$. At present, the treatment methods for oral problems of leukemia patients after chemotherapy mainly include taking vitamin B elements, mucosal protective agents, fluconazole, lidocaine mixture and other methods. However, due to the long course of disease and poor therapeutic effects of various drugs, the oral treatment of patients after chemotherapy has become an important research direction. In this paper, the changes of oral flora and oral environment in leukemia patients after chemotherapy were investigated and then the effects of taking propolis on oral flora structure and immune microenvironment in leukemia patients after chemotherapy were understood, which brought good news for the prognosis and treatment of leukemia patients.

\section{MATERIALS AND METHODS}

\section{General data:}

Experimental objects: The subjects were 112 leukemia patients who received chemotherapy in Hubei Medical
College from March 2017 to June 2019. According to the random number method, the patients were divided into control group and observation group with 56 cases in each group. There was no obvious difference in age, sex and course of disease among patients in each group.

Inclusion criteria: All patients were clinically diagnosed as leukemia; all patients were treated by chemotherapy; all patients voluntarily signed the informed consent of this study and voluntarily participated in this investigation.

Exclusion criteria: Patients with other complicated severe diseases; patients have cognitive dysfunction; patients during lactation or pregnancy.

\section{Methods:}

Method for preparation and use of medicine: Weigh 70 $\mathrm{g}$ of propolis, pulverize it, dissolve it in $75 \%$ ethanol to make the propolis solution with a concentration of $0.7 \mathrm{~g} /$ $\mathrm{ml}$. Store the solution in a brown bottle, seal it for $1 \mathrm{mo}$ and then filter it with gauze for use. When in use, clean the oral cavity first, suck the affected part dry and keep it dry and then apply the solution to the affected part for treatment twice a day.

Experimental treatment method: After 1-2 w of chemotherapy, the patients were examined by bone marrow puncture and the relationship between the degree of bone marrow suppression and the occurrence of oral mucositis and neutrophils was analyzed. Then, the patients were treated in groups.

Control group: Traditional Chinese Medicine (TCM) powder was evenly applied to the oral mucosa and other wound surfaces of 56 leukemia patients after chemotherapy three times a day.

Observation group: The oral cavity of 56 leukemia patients after chemotherapy were cleaned with $3 \%$ hydrogen peroxide twice a day and then dried with air gun. Then, the oral mucosa was sprayed and smeared with physiological saline mixture containing $10 \%$ propolis. After a thin film was formed, the oral mucosa was dried with air gun. The end time of treatment should be $30 \mathrm{~min}$ before the patient ate.

\section{Evaluation criteria of curative effect:}

According to the original guiding principle of clinical research of antibacterial drugs in 1993, the evaluation criteria is shown in Table 1. 


\begin{tabular}{lc}
\hline Judgement & Manifestation \\
\hline Cured & $\begin{array}{c}\text { Oral mucosa is normal, without fever and pain. The results } \\
\text { of mycological and bacteriological examination are negative } \\
\text { Oral mucosa is hyperemia, without fever, and the pain is } \\
\text { relieved. The }\end{array}$ \\
Effective & $\begin{array}{c}\text { Tesults of mycological and bacteriological examination are } \\
\text { negative }\end{array}$ \\
Ineffective & $\begin{array}{c}\text { Oral ulcer is reduced and fever is relieved. Results of } \\
\text { mycological and bacteriological examination may be positive } \\
\text { The improvement effect of oral ulcer and fever is not } \\
\text { obvious. Results of mycological and bacteriological } \\
\text { examination are positive }\end{array}$
\end{tabular}

Bacteriological examination:

$1 \mathrm{~cm}^{2}$ samples were collected by sterile curette from oral mucosa of patients after chemotherapy and propolis treatment and then inoculated on agar plate of bovine heart and brain juice and cultured at $37^{\circ}$ for $4 \mathrm{~d}$ with 10 $\% \mathrm{H}_{2}, 80 \% \mathrm{~N}_{2}$ and $10 \% \mathrm{CO}_{2}$. The separated bacteria were cultured in Brain Heart Infusion (BHI-S) and common stock blood agar plates respectively and then put into $37^{\circ}$ common incubator for $24 \mathrm{~h}$ of oxygen-tolerant culture. After the culture, the bacteria was identified and the identification standard was based on Berger's system method, such as staining, morphology, oxygen tolerance test and biochemical test. The number, detection rate and composition ratio of bacteria were calculated.

Detection of the messenger Ribonucleic Acid (mRNA) expression levels of Interleukin 22 (IL-22) and Tumour Necrosis Factor alpha (TNF- $\alpha$ ) in the oral cavity of the subjects by Reverse Transcription Polymerase Chain Reaction (RT-PCR):

The tissue site of the patient's oral mucosa was gently scraped with sterile scraper. Ribonucleic Acid (RNA) in the sample was extracted with RNA extraction kit and then reverse transcription was carried out quickly. RT-PCR was used to detect the reverse transcription products and Betaactin was used as internal reference to detect the mRNA expression levels of IL-22 and TNF- $\alpha$ in oral cavity.

Detection of the expression levels of chemokine (C-X-C motif) ligand 9 (CXCL9) and chemokine (C-X-C motif) ligand 10 (CXCL10) in the oral cavity of the subjects by Enzyme Linked Immunosorbent Assay (ELISA):

The tissue site of oral mucosa was gently scraped with sterile scraper and the expression levels of chemokines CXCL9 and CXCL10 in the oral cavity of the subjects were detected according to the kit instructions.

\section{Detection of the expression levels of IL-22 and TNF- $\alpha$ proteins in the oral cavity of the subjects:}

Sterile scraper was used to gently scrape the oral mucosa tissue. After adding a certain volume of tissue protein lysate, the mixture was incubated at low temperature for $30 \mathrm{~min}$. After centrifugation at $3000 \mathrm{~g} / \mathrm{min}$ for $5 \mathrm{~min}$, the supernatant was taken, mixed with protein buffer at a ratio of 1: 4 , boiled in boiling water bath for $5 \mathrm{~min}$, and stored at $-20^{\circ}$ for later use.

The gel prepared in advance was put into gel buffer and the sample was loaded with $10-30 \mathrm{ng}$ protein per well. Then the electrophoresis experiment was carried out at $230 \mathrm{~V}$ and $300 \mathrm{~mA}$ for $1 \mathrm{~h}$. After electrophoresis, it was transferred to Polyvinylidene Fluoride (PVDF) membrane and the expression levels of IL-22 and TNF- $\alpha$ proteins in samples were detected according to the following steps: primary antibody incubation, elution, secondary antibody incubation, elution and color development.

\section{Statistical treatment:}

Statistical Package for the Social Sciences (SPSS) 19.0 was used for statistical analysis of experimental data and one way Analysis of Variance (ANOVA) was used for analysis of differences among groups. The results were expressed as $(\overline{\mathrm{x}} \pm \mathrm{s})$. It was considered that when $\mathrm{p}>0.05$, there was no statistical significance between the data.

\section{RESULTS AND DISCUSSION}

The relationship between oral mucositis of patients with leukemia after chemotherapy and granulocyte number and bone marrow suppression degree within 1-2 w after chemotherapy is shown in Table 2. Compared with $1 \mathrm{w}$ after chemotherapy, the frontal incidence of oral mucositis was increased after $2 \mathrm{w}$ of chemotherapy. The neutrophils 
TABLE 2: THE RELATIONSHIP BETWEEN ORAL MUCOSITIS OF PATIENTS WITH LEUKEMIA AFTER CHEMOTHERAPY AND GRANULOCYTE NUMBER AND BONE MARROW SUPPRESSION DEGREE

\begin{tabular}{lcc}
\hline Item & 1 w after chemotherapy & 2 w after chemotherapy \\
\hline Oral mucositis $(\%)$ & $35.13 \pm 3.76$ & $65.17 \pm 2.63 a$ \\
Neutrophils number $\left(\times 10^{9} / \mathrm{l}\right)$ & $0.95 \pm 0.09$ & $0.25 \pm 0.08 \mathrm{a}$ \\
Degree of bone marrow hyperplasia & $\mathrm{IV}$ & $\mathrm{V}$ \\
\hline
\end{tabular}

Note: $A$ indicates $p<0.01$ compared with $1 \mathrm{w}$ after chemotherapy

number was decreased to $(0.25 \pm 0.08) \times 10^{9} / 1$ and the bone marrow hyperplasia was aggravated.

Curative effect of propolis on patients with leukemia after chemotherapy oral mucositis is shown in Table 3. Compared with the control group, the cure rate of the patients in the observation group reached $55.36 \%$ and the ineffective rate was only $5.37 \%$.

Effect of propolis on oral mucositis and neutrophils recovery time of patients with leukemia is shown in Table 4. Compared with the control group, the recovery time of cavity mucositis and neutrophils in the observation group was reduced. Effect of propolis on flora structure of oral mucositis in patients with leukemia after chemotherapy is shown in Table 5. Compared with after chemotherapy, the total amount of bacteria detected in patients treated with propolis was decreased, in which the composition ratio of Verona and Fusobacterium was increased and the composition ratio of other detected bacteria was decreased.

The results of RT-PCR are shown in fig.1. It can be seen from the figure that the mRNA expression levels of IL-22 and TNF- $\alpha$ in the oral cavity of patients in the observation group were decreased compared with those in the control group.

The levels of chemokines CXCL9 and CXCL10 in oral cavity of subjects were detected by ELISA. The results were shown in fig. 2 . It can be seen from fig. 2 that compared with the control group, the levels of chemokines CXCL9 and CXCL10 in the oral cavity of the patients in the observation group were decreased.

The expression results of IL-22 and TNF- $\alpha$ in the oral cavity of subjects detected by Western blot were shown in

TABLE 3: CURATIVE EFFECT OF PROPOLIS ON PATIENTS WITH LEUKEMIA AFTER CHEMOTHERAPY ORAL MUCOSITIS (CASE (\%))

\begin{tabular}{lcccc}
\hline Group & Ineffective & Effective & Highly effective & Cured \\
\hline Control group & $14(25.00)$ & $10(17.86)$ & $9(16.07)$ & $23(41.07)$ \\
Observation group & $3(5.37)^{\mathrm{a}}$ & $8(14.27)$ & $14(25.00)^{\mathrm{a}}$ & $31(55.36)^{\mathrm{a}}$ \\
\hline
\end{tabular}

Note: $A$ indicates $p<0.01$ compared with control group

TABLE 4: EFFECT OF PROPOLIS ON ORAL MUCOSITIS AND NEUTROPHILS RECOVERY TIME OF PATIENTS WITH LEUKEMIA

\begin{tabular}{lcc}
\hline Group & Recovery time of oral mucositis & Recovery time of neutrophils \\
\hline Control group & $24.19 \pm 3.76$ & $30.72 \pm 3.13$ \\
Observation group & $15.11 \pm 3.41^{\mathrm{a}}$ & $29.67 \pm 2.75$ \\
\hline
\end{tabular}

Note: $A$ indicates $p<0.01$ compared with control group

TABLE 5: EFFECT OF PROPOLIS ON FLORA STRUCTURE OF ORAL MUCOSITIS IN PATIENTS WITH LEUKEMIA AFTER CHEMOTHERAPY

\begin{tabular}{|c|c|c|c|c|c|c|}
\hline \multirow{2}{*}{$\begin{array}{l}\text { Detected } \\
\text { bacteria }\end{array}$} & \multicolumn{3}{|c|}{ After chemotherapy } & \multicolumn{3}{|c|}{ After propolis treatment } \\
\hline & Positive rate & $\begin{array}{c}\text { Detectable } \\
\text { quantity }(\lg X)\end{array}$ & $\begin{array}{c}\text { Composition } \\
\text { ratio (\%) }\end{array}$ & Positive rate & $\begin{array}{c}\text { Detectable } \\
\text { quantity (lgX) }\end{array}$ & $\begin{array}{l}\text { Composition } \\
\text { ratio (\%) }\end{array}$ \\
\hline $\begin{array}{l}\text { Staphylococcus } \\
\text { aureus }\end{array}$ & 18.17 & $4.81 \pm 0.64$ & 2.02 & 9.09 & $3.01 \pm 0.42$ & $0.42 a$ \\
\hline Streptococcus & 90.89 & $5.34 \pm 0.84$ & 67.65 & 90.89 & $4.08 \pm 0.83$ & 65.62 \\
\hline Neisseria & 27.27 & $4.61 \pm 0.94$ & 6.70 & 22.73 & $3.51 \pm 1.30$ & $1.46 a$ \\
\hline Veillonella & 18.18 & $5.06 \pm 0.61$ & 4.01 & 18.18 & $3.28 \pm 1.01$ & $9.92 a$ \\
\hline
\end{tabular}




\begin{tabular}{lcccccc}
$\begin{array}{l}\text { Prevotella } \\
\text { Fusobacterium }\end{array}$ & 18.18 & $4.14 \pm 1.13$ & 2.27 & 18.18 & $3.47 \pm 1.14$ & $3.05 \mathrm{a}$ \\
$\begin{array}{l}G^{N} \text { anaerobic } \\
\text { bacillus }\end{array}$ & 9.09 & $4.28 \pm 1.20$ & 2.73 & 18.18 & $3.58 \pm 0.96$ & $10.56 \mathrm{a}$ \\
$\begin{array}{l}\text { GPanaerobic } \\
\text { bacillus }\end{array}$ & 36.36 & $4.29 \pm 0.98$ & 5.07 & 27.27 & $2.89 \pm 0.70$ & $0.89 \mathrm{a}$ \\
$\begin{array}{l}\mathrm{CO}_{2} \text { cellulomonas } \\
\text { Total amount }\end{array}$ & 27.82 & $4.30 \pm 1.13$ & 5.48 & 40.09 & $3.19 \pm 0.86$ & 5.07 \\
\hline
\end{tabular}

Note: $A$ indicates $p<0.01$ compared with after propolis treatment

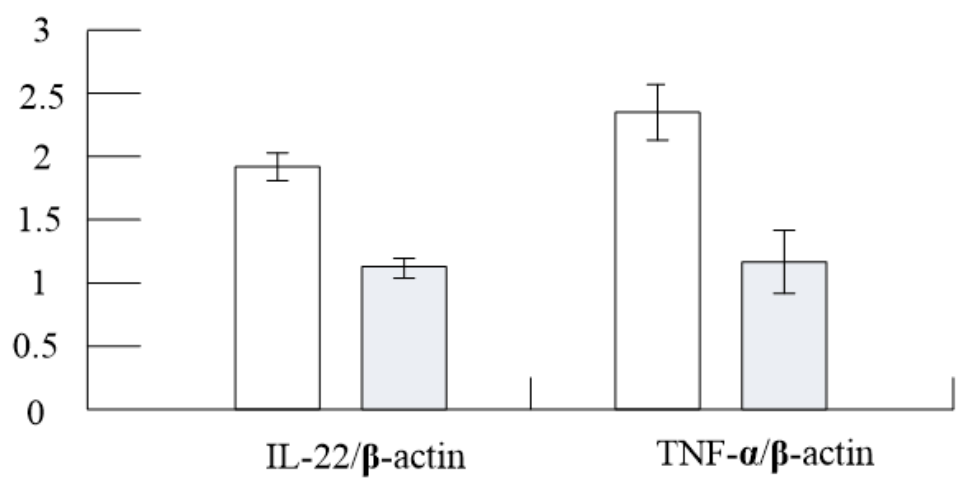

Fig. 1: mRNA expression levels of IL-22 and TNF- $\alpha$ in oral cavity of subjects, ( $\square$ ): Control group, ( $\square$ ): Observation group

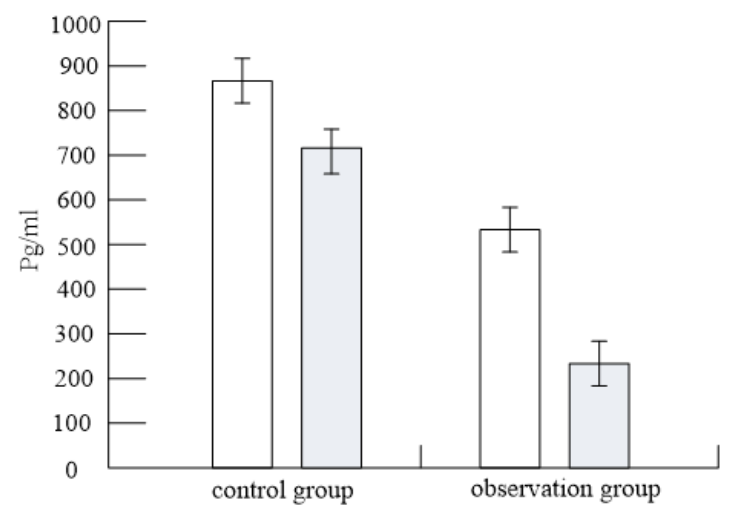

Fig. 2: Expression levels of chemokinesCXCL9 and CXCL10 in oral cavity of subjects, ( $\square)$ : CXCL9, ( $\square)$ : CXCL10

TABLE 6: EXPRESSION LEVELS OF IL-22 AND TNF- $\alpha$ PROTEINS IN ORAL CAVITY OF SUBJECTS

\begin{tabular}{lcc}
\hline Group & IL-22/B-actin & TNF-a/B-actin \\
\hline Control group & $32.19 \pm 3.76$ & $48.72 \pm 3.13$ \\
Observation group & $15.11 \pm 3.41$ & $29.67 \pm 2.75$ \\
\hline
\end{tabular}

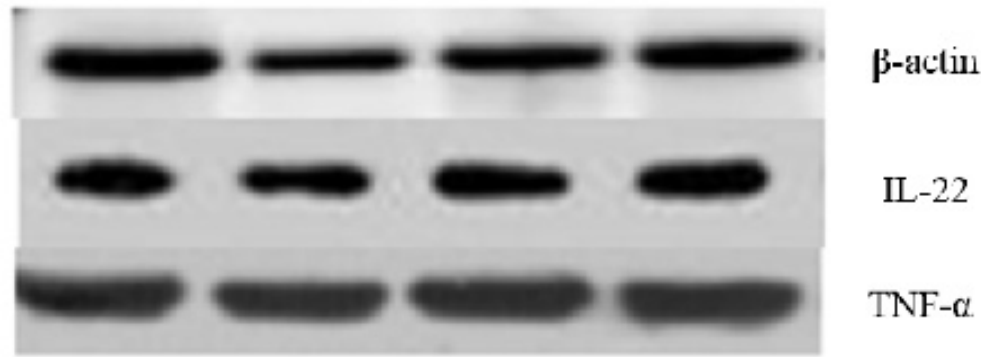

Fig. 3: Expression levels of IL-22 and TNF- $\alpha$ proteins in oral cavity of subjects 
Table 6 . It can be seen from Table 6 that compared with the control group, the expression levels of IL-22 and TNF- $\alpha$ proteins in the oral cavity of patients in the observation group were decreased. The results were shown in fig. 3 .

In recent years due to the increase in the intensity, type and dose of chemotherapy, monoclonal antibodies, large doses of immunosuppressants and targeted therapy and application of broad-spectrum antibiotics, some fungal infections have increased in newly diagnosed or relapsed leukemia patients and the incidence of oral mucosa destruction in patients has reached $40 \%$ to 80 $\%{ }^{[11]}$. Therefore, it is of great significance to find suitable methods for the protection and treatment of oral internal environment of leukemia patients after chemotherapy.

In this study, it was found that oral mucositis was alleviated in patients with leukemia after chemotherapy and the total amount of bacteria detected and the composition ratio of bacteria changed. At the same time, the expression of inflammatory factors IL-22, TNF- $\alpha$ and the levels of CXCL9 and CXCL10 were decreased.

At present, chemotherapy is one of the main methods to treat leukemia clinically. As a common complication after chemotherapy, the oral ulcer has an incidence reaching 20 $\%-80 \%$ and its complications can promote the structural imbalance of oral flora ${ }^{[9]}$. Kim et al. ${ }^{[12]}$ found that the most common pathogen in 38 patients with acute leukemia after chemotherapy is Candida albicans, which belongs to the main pathogen in fungal infection and has the ability to inhibit the immunity of the body. It is found that the number of leukocytes in leukemia patients is decreased gradually during chemotherapy and the immune function of the body is also declining. Therefore, it is easy to suffer microorganisms attack, causing secondary infection in the oral cavity. In addition, chemotherapy drugs mostly have immunosuppressive effect. As a result, the humoral immunity and cellular immunity of the body are altered, resulting in dysbacteriosis ${ }^{[13]}$. According to clinical reports, while routine oral care is given to leukemia patients after chemotherapy, certain nursing interventions are taken. The results show that the number of patients with oral ulcer in the observation group is lower than that in the experimental control group and the incidence of I-IV degree of oral ulcer is lower than that in the control group, indicating that nursing intervention for patients complicated with oral ulcer after chemotherapy can effectively alleviate the pain and inflammation of patients and then achieve the effect of curing oral ulcer ${ }^{[14]}$.

It is reported that propolis has obvious clinical efficacy in the treatment of oral diseases ${ }^{[15]}$. In the study of broad- spectrum antibacterial effect, it is found that the inhibitory concentration of propolis on melanin-producing main pathogenic bacteria in periodontitis patients is equivalent to that of $0.1 \%$ nitrofile and the killing rate of propolis on Staphylococcus aureus and Escherichia coli is over $99.9 \%{ }^{[16]}$. At the same time, the antibacterial experiment results of main caries causing drugs show that the antibacterial effect of propolis is significantly higher than that of other TCM and the antibacterial concentration of propolis to lactobacillus and streptococcus mutans was $1.56 \%{ }^{[17]}$. Oral mucosa leukoplakia is a common disease occurring in oral mucosa. Studies have found that the cure rate can reach $62 \%$ and the effective rate of the drug can reach $100 \%$ when using the compound drug containing $50 \%$ propolis. Studies have also found that propolis has antibacterial effect and can be used in combination with many antibiotics to significantly improve its antibacterial ability and action time. Long-term administration will not cause flora imbalance in patient's oral cavity and will not cause drug resistance ${ }^{[18]}$. IL-22 is secreted by $\mathrm{T}$ helper type 22 (Th22) and T helper 17 (Th17) cells and plays an important role in the anti-infection immunity of mucous membrane. Its expression site is tissue specific, mainly in epithelial cells. It can induce inflammatory factors such as chemokines, acute reactive proteins and cytokines and antibacterial peptides such as regenerating family proteins and $\beta$-defensins and is considered to play an important role in the early immune period of oral mucositis disease. As one of the important inflammatory factors, TNF- $\alpha$ can enhance the phagocytic activity of macrophages and neutrophils and promote the maturation of antigenpresenting cells. It is found that IL- 22 and TNF- $\alpha$ can effectively reduce the growth of Candida albicans, inhibit keratinocyte apoptosis and maintain the integrity of epidermal structure. Literature reports have confirmed that IL-22 and TNF- $\alpha$ can induce up regulation of innate immunity related gene expression in human primary keratinocytes.

To sum up, propolis could alleviate the symptoms of oral mucositis after leukemia chemotherapy, adjust the structure of oral flora and improve the oral immune microenvironment by reducing the expression of inflammatory factors.

\section{Conflict of interests:}

The authors declare no conflict of interest.

\section{REFERENCES}

1. Deghbar N, Mezioug D, Kahina T, Medjdoub Y-M, TouilBoukoffa C. Antihydatic and immunomodulatory effects of Algerian propolis ethanolic extract: In vitro and in vivo study. Asian Pac J Trop Med 2019;12(3):106. 
2. Kabała-Dzik A, Rzepecka-Stojko A, Kubina R, Iriti M, Wojtyczka RD, Buszman E, et al. Flavonoids, bioactive components of propolis, exhibit cytotoxic activity and induce cell cycle arrest and apoptosis in human breast cancer cells MDA-MB-231 and MCF-7-a comparative study. Cell Mol Biol 2018;64(8):1-10.

3. Zarei M, Jafarian AH, Harandi A, Javidi M, Gharechahi M. Evaluation of the expression of VIII factor and VEGF in the regeneration of non-vital teeth in dogs using propolis. Iran J Basic Med Sci 2017;20(2):172-77.

4. Jug M, Koncic MZ, Kosalec I. Modulation of antioxidant, chelating and antimicrobial activity of poplar chemo-type propolis by extraction procures. LWT-Food Sci Technol 2014;57(2):530-7.

5. Matela AM, Hagström J, Ruokonen H. Lichen sclerosus of the oral mucosa: clinical and histopathological findings. Review of the literature and a case report. Acta Odontol Scand 2018;76(5):364-73.

6. Fox LC, Cummins KD, Costello B, Yeung D, Cleary R, Forsyth $\mathrm{C}$, et al. The incidence and natural history of dasatinib complications in the treatment of chronic myeloid leukemia. Blood Adv 2017;1(13):802-11.

7. Choi SE, Kim HS. Sodium bicarbonate solution versus chlorhexidine mouthwash in oral care of acute leukemia patients undergoing induction chemotherapy: a randomized controlled trial. Asian Nurs Res 2012;6(2):60-6.

8. Tang J, Zhang R, Guo M, Shao L, Liu Y, Zhao Y, et al. Nucleosome-inspired nanocarrier obtains encapsulation efficiency enhancement and side effects reduction in chemotherapy by using fullerenol assembled with doxorubicin. Biomaterials 2018;167:205-15.

9. Leguisamo NM, Gloria HC, Kalil AN, Martins TV, Azambuja $\mathrm{DB}$, Meira LB, et al. Base excision repair imbalance in colorectal cancer has prognostic value and modulates response to chemotherapy. Oncotarget 2017;8(33):54199-214.

10. Kilic SS, K1lıc S, Crippen MM, Varughese D, Eloy JA, Baredes $\mathrm{S}$, et al. Predictors of clinical-pathologic stage discrepancy in oral cavity squamous cell carcinoma: A National Cancer Database study. Head Neck 2018;40(4):828-36.

11. Bayram C, Yaralı N, Fettah A, Demirel F, Tavil B, Kara A, et al. Evaluation of endocrine late complications in childhood acute lymphoblastic leukemia survivors: A Report of a SingleCenter Experience and Review of the Literature. Turk J Hematol 2017;34(1):40-5.
12. Kim D, Kwon S-J, Wu X, Sauve J, Lee I, Nam J, et al. Selective killing of pathogenic bacteria by antimicrobial silver nanoparticle-Cell wall binding domain conjugates. ACS Appl Mater Interfaces 2018;10(16):13317-24.

13. Krupar R, Schreiber C, Offermann A, Lengerke C, Sikora AG, Thorns $\mathrm{C}$, et al. In silico analysis of anti-leukemia immune response and immune evasion in acute myeloid leukemia. Leuk Lymphoma 2018;59(10):2493-96.

14. Odunyemi FT, Ndikom CM, Oluwatosin OA. Effect of nursing intervention on mothers' knowledge of cervical cancer and acceptance of human papillomavirus vaccination for their adolescent daughters in Abuja-Nigeria. Asia Pac J Oncol Nurs 2018;5(2):223-30.

15. Rudresha $\mathrm{AH}$, Chaudhuri $\mathrm{T}$, Lakshmaiah $\mathrm{KC}$, Babu $\mathrm{KG}$, Dasappa L, Jacob LA, et al. Induction chemotherapy in locally advanced T4b oral cavity squamous cell cancers: A regional cancer center experience. Indian J Cancer 2017;54(1):35-8.

16. Li M, Gao L, Schlaich C, Zhang J, Donskyi IS, Yu G, et al. Construction of functional coatings with durable and broadspectrum antibacterial potential based on mussel-inspired dendritic polyglycerol and in situ-formed copper nanoparticles. ACS Appl Mater Interfaces 2017;9:35411-8.

17. Bueno-Silva B, Koo H, Falsetta ML, Alencar SM, Ikegaki M, Rosalen PL. Effect of Neovestitol-vestitol containing Brazilian red propolis on biofilm accumulation in vitro and dental caries development in vivo. Biofouling 2013;29(10):1233-42.

18. Rouhani A, Erfanzadeh M, Jafarzadeh H, Najafi E. Comparison of residual triple antibiotic paste, propolis and calcium hydroxide on root canal walls in natural open apex teeth: An in vitro study. Iran Endod J. 2018;13(1):25-9.

This is an open access article distributed under the terms of the Creative Commons Attribution-NonCommercial-ShareAlike 3.0 License, which allows others to remix, tweak, and build upon the work non-commercially, as long as the author is credited and the new creations are licensed under the identical terms



